\title{
Bullying Among Adolescents With Autism Spectrum Disorders: Prevalence and Perception
}

\author{
Eeske van Roekel • Ron H. J. Scholte • \\ Robert Didden
}

Published online: 8 August 2009

(c) The Author(s) 2009. This article is published with open access at Springerlink.com

\begin{abstract}
This study examined: (a) the prevalence of bullying and victimization among adolescents with ASD, (b) whether they correctly perceived bullying and victimization, and (c) whether Theory of Mind (ToM) and bullying involvement were related to this perception. Data were collected among 230 adolescents with ASD attending special education schools. We found prevalence rates of bullying and victimization between 6 and 46\%, with teachers reporting significantly higher rates than peers. Furthermore, adolescents who scored high on teacher- and self-reported victimization were more likely to misinterpret non-bullying situations as bullying. The more often adolescents bullied, according to teachers and peers, and the less developed their ToM, the more they misinterpreted bullying situations as non-bullying. Implications for clinical practice are discussed.
\end{abstract}

Keywords Bullying - Perception - Autism - Adolescents · Prevalence Theory of Mind

\section{Introduction}

Bullying in school is a common problem worldwide (Smith et al. 1999). The estimated rates of bullying and victimization worldwide vary from 5 to $38 \%$ for girls, and from 6 to $41 \%$ for boys (Due et al. 2005). Bullying is a subtype of aggression that may be defined as a systematic abuse of power (Smith and Sharp 1994), in which a person (i.e., the victim) is exposed, repeatedly and over

E. van Roekel $(\varangle) \cdot$ R. H. J. Scholte $\cdot$ R. Didden

Behavioural Science Institute, Radboud University Nijmegen,

P.O. Box 9104, 6500 HE Nijmegen, The Netherlands

e-mail: g.vanroekel@pwo.ru.nl time, to negative actions on the part of one or more other students (Olweus 1993). Bullying can have serious consequences and is related to later behavioral and emotional problems in bullies as well as in victims (Scholte et al. 2007). Until now, research on bullying in adolescence has focused predominantly on adolescents attending general education settings, while surprisingly little attention has been given to special needs adolescents such as those with autism spectrum disorders (ASD). In special needs children and adolescents, peer victimization has been found to be more prevalent in children with special health care needs (Van Cleave and Davis 2006), Specific Language Impairment (Conti-Ramsden and Botting 2004), chronic disease (Nordhagen et al. 2005), internalizing problems and psychosomatic symptoms (Kumpulainen et al. 1998), learning disabilities and co-morbid psychiatric problems (Baumeister et al. 2008), and in children who were more likely to have had contact with mental health services in the past 3 months (Kumpulainen et al. 2001). Furthermore, bullying was more prevalent among children with behavioral, emotional or developmental problems (Van Cleave and Davis 2006), attention deficit disorder, depression and oppositional/conduct disorder (Kumpulainen et al. 2001), and psychiatric problems (Nordhagen et al. 2005). None of these studies have examined bullying and victimization among adolescents with ASD, who may be especially at risk for bullying and victimization. There are at least two reasons why special needs children and adolescents are at higher risk for bullying and victimization: they are less socially competent (Whitney et al. 1992) and have fewer friendships (Martlew and Hodson 1991). These reasons may also explain why adolescents with ASD may be at higher risk for bullying and victimization, but none of the studies on adolescents with special needs have examined this. 
Therefore, the purpose of this study is to examine bullying and victimization among adolescents with ASD.

Prevalence of Bullying and Victimization Among Adolescents With ASD

One reason why adolescents with ASD may be at higher risk for victimization is that they have deficits in developing normal social interactions and relationships as well as deficits in understanding the behavior of others (Frith and Hill 2004). In general education settings, adolescents with ASD may be at higher risk for victimization because of characteristics related to ASD, such as their deficits in communication and their stereotyped behavior and interests (Haq and Le Couteur 2004). Furthermore, they may also be at higher risk for victimization because of their problems with developing friendships (Bauminger and Kasari 2000; Chamberlain et al. 2007), which is a risk factor for victimization (Hodges et al. 1999). To our knowledge, only two studies have examined peer victimization among children and adolescents with Asperger syndrome in general education settings (Little 2001, 2002). Results of these studies showed that, compared to the nondisabled population, victimization rates were four times higher in this sample, with up to $75 \%$ of adolescents with Asperger being victimized (Little 2001). Furthermore, Little (2002) found that $94 \%$ of the children with either Asperger Syndrome or Nonverbal Learning Disability were victimized in the past year, as reported by their mothers.

There may also be several reasons why adolescents with ASD are at higher risk for bullying others, both in general and in special education settings. First, adolescents with ASD are often found to show increased levels of aggressive behaviors (Matson and Nebel-Schwalm 2007; McClintock et al. 2003). Since bullying can be considered a specific kind of aggression, adolescents with ASD might also be more at higher risk for bullying others. Second, because adolescents with ASD have limited insight in social processes (Frith and Hill 2004), they may not be aware of the consequences of their own behavior, and may thus bully, without being aware of it. Previous research on the association between ASD and perpetrating of bullying among adolescents has to some extent supported these hypotheses. In general education settings, it has been found that mostly, adolescents with ASD were as likely to bully as typically developing adolescents. However, when adolescents with ASD had co morbid Attention-Deficit/Hyperactivity Disorder, they turned out to be five times more likely to bully than neurotypical adolescents (Montes and Halterman 2007).

Until now, studies on ASD and bullying involvement have been conducted in general education settings.
Empirical data on the association between ASD and bullying involvement in special education are still lacking. Therefore, the focus of the present study is on examining bullying and victimization among adolescents with ASD in special education.

\section{Perceptions of Bullying}

The perception of bullying and victimization consists of two main parts: first, one has to perceive that the action is aggressive in nature, and second, one has to perceive that this aggression is directed towards a person who is relatively weaker than the aggressor(s), which refers to an imbalance of power. A7lthough it can be expected that bullying and victimization are related to ASD, an important question is whether adolescents with ASD can actually perceive bullying or victimization when it occurs. Individuals with ASD have deficits in Theory of Mind (ToM) skills, which is the ability of individuals to attribute mental states to themselves and to others in order to explain and predict behavior (Baron-Cohen 2000). Mental states include beliefs, desires, intentions, perceptions, imagination, and emotions (Repacholi and Slaughter 2003). People with ASD are supposed to have a deficit in the understanding of minds and mental states of other people (Frith and Hill 2004), and consequently also in understanding the intentions of others. In highfunctioning autism, ToM abilities are more developed, but the adolescents still score significantly lower than non-disabled peers (Baron-Cohen et al. 1997; Happé 1994). Because of these deficits in social insight, adolescents with ASD may be less able to recognize bullying than adolescents without ASD. Unlike adolescents with ASD, we expect typically developing adolescents to be able to recognize bullying as they are likely to possess the social skills and social insight to perceive bullying behavior correctly.

A small number of studies have revealed that adolescents with autism are not able to interpret social situations correctly, possibly as a result of their less well developed social insight. For example, Pierce et al. (1997) examined social perception in children with autism by showing videotaped vignettes of both positive and negative social interactions with varying numbers of social cues (e.g., verbal content, tone, nonverbal behavior with object, and nonverbal behavior without object). They found that children with autism scored significantly lower on interpreting social situations than the comparison groups when the social perception stories contained more than one cue. Loveland et al. (2001) found that the group with ASD had significantly more problems in detecting inappropriate behaviors in video fragments than the non-ASD group, but only for scenes that included 
verbal behavior. These results imply that children with ASD can understand and recognize simple (one-cued) social situations, but fail to correctly understand more complex social situations. It can thus be expected that adolescents with ASD will have difficulties with recognizing bullying behavior.

However, not all adolescents with ASD will be equally disabled in recognizing bullying behavior, because differences in this group exist in several relevant characteristics that are important in the perception of bullying. The first relevant characteristic is ToM. It may be expected that adolescents with a higher developed ToM are better in the perception of bullying than adolescents with a lower developed ToM. The second characteristic that may be important in the perception of bullying is the level of victimization. Adolescents who report to be frequently victimized have experienced many negative interactions and situations, and thus may be biased in their perception of social situations. The final relevant characteristic is the level of bullying. Results from studies on social perception in aggressive children and adolescents reveal that they have deficits in their perception. Aggressive children and adolescents perceive, interpret, and make decisions about social stimuli in ways that increase the likelihood that they will engage in aggressive acts (Crick and Dodge 1996). Aggressive children attribute hostile intentions to ambiguous provocation situations more often than other children, and they expect positive outcomes from aggressive acts and perceive aggression as a useful means for obtaining desired goals (Crick and Dodge 1996). Furthermore, several studies have found that stronger anger attribution bias (perceiving anger from non-anger cues) predicted higher levels of aggression (Fine et al. 2004; Schultz et al. 2000). Since bullying is a subtype of aggression, it may be expected that especially bullies show deficits in their perception of bullying.

\section{The Present Study}

The main hypothesis of this study is that adolescents with ASD have difficulties in recognizing bullying behavior. The specific aims of the present study were: (a) to examine the prevalence of bullying and victimization among adolescents with ASD, and (b) to examine whether adolescents with ASD are able to perceive bullying and victimization and which factors are related to this perception. The data were collected among adolescents with ASD attending three special education schools by administering questionnaires among these adolescents and their teachers, and by examining their evaluation of videotaped fragments of social interactions. In this study, we will focus on adolescents with ASD, we will not distinguish between the different subtypes of ASD.

\section{Methods}

\section{Participants}

The sample for this study consisted of adolescents with ASD who attended schools for special secondary education in the Netherlands. The participants were derived from three special education schools, all located in the eastern part of The Netherlands. These schools were primarily focused on educating adolescents with ASD, thus all students from these schools had a diagnosis of a disorder in the autistic spectrum. The diagnoses in this sample were the following: Autism Spectrum Disorder (ASD; $n=35$ ), Pervasive Developmental Disorders Not Otherwise Specified (PDD-NOS, $n=123$ ), and Asperger Syndrome (AS; $n=29$ ). Several adolescents had an additional diagnosis of Attentional Deficit/Hyperactivity Disorder (ADHD; $n=31$ ). These diagnoses were set by qualified psychiatrists or psychologists, based on DSM-IV criteria. Participants were 230 adolescents with ASD, of whom 208 were boys. They were 12-19-years-old ( $M=14.97$, $\mathrm{SD}=1.45$ ), and the level of education varied from vocational to pre-university education. Their mean total IQ was $97.07(\mathrm{SD}=14.64)$.

Furthermore, a control group was selected to check whether the perceptions of adolescents with ASD differed from the perceptions of adolescents without ASD. This control group consisted of 24 adolescents ( 22 boys, 2 girls) who followed secondary education. These adolescents were group matched with the group of adolescents with ASD on educational level, age $(M=15.5)$, and sex. As was the case with the ASD adolescents, passive informed consent from these adolescents and their parents was obtained. Before starting the study, a pilot study was conducted on a small sample of adolescents to pilot test the video clips (see "Measures"). This pilot sample contained 26 adolescents (11 boys, 15 girls), aged between 12 and 14 years, with an educational level comparable to the educational level of the ASD adolescents and control group adolescents. Both the control sample and the pilot sample were recruited by contacting schools and parents by letters and asking for parental consent.

\section{Procedure}

The special secondary education schools were recruited by contacting the principals by telephone. After the schools consented to participate, parents of 242 adolescents were sent a letter in which they were informed about the aims of the study and they were asked to give their consent. Parents of twelve students refused to give their consent, because the research would be too intrusive for their children, or because their children were already involved in other 
studies or clinical research. Therefore, our final sample consisted of 230 adolescents with ASD.

Data were collected during classroom visits by the first author. The questionnaires were administered group wise. To maximize the probability that all adolescents had the same definition of bullying in mind, the definition of bullying was printed on a questionnaire, and the experimenter read the definition out loud in the class to make sure the participants understood the concept of bullying. Subsequently, the participants were asked whether they understood the definition and they were instructed to ask for clarification if they had any questions. The video fragments were shown to participants in their classroom. After each fragment, the video was paused, and the participants were asked to write down on the questionnaire whether or not that fragment contained bullying (yes or no). The questionnaire and the video fragments were administered within $45 \mathrm{~min}$. Participants were allowed to take a 5 min break between the administration of the questionnaire and the video fragments.

The ToM task was computerized, and was individually administered on computers with an internet connection. The instructions for the ToM task were given on screen. This task did not need any additional instruction or supervision from the investigator or the teacher. The duration of this task was $15 \mathrm{~min}$.

\section{Measures}

Peer-ratings on bullying and victimization. To measure peer-reported levels of bullying and victimization, participants had to rate on a 5-point Likert scale how well each of their class members fitted two behavioral descriptions related to bullying and victimization. The item for bullying was 'bullies other children', and the item for victimization was 'is victimized'. The answer categories were: (1) 'never', (2) 'a few times a year', (3) 'once a month', (4) 'once a week', and (5) 'several times a week'. The participants were provided with a list of names of their class members, and had to rate how often each class member displayed the behavior described. The following description of bullying was given: 'Bullying is when a child or a group children regularly say unpleasant or mean things to another child, or laugh at another child, who can not defend himself/herself. It is also bullying when a child is regularly hit, kicked, threatened, locked up, or when his or her belongings are taken or destroyed. It is also bullying when a child is regularly shut out, or when other children spread rumors or lies about him/her. It is not bullying when two children of the same strength argue or fight' (Olweus 1991; Whitney and Smith 1993). The scores were summed for every participant, and then divided by the number of raters in that class to account for differences in class size.
This final score indicates how often that participant bullies or is bullied (varying from never to several times a week). The scores on all ratings (peer-, teacher- and self-) could vary between 1 and 5 .

Teacher-ratings on bullying and victimization. The teachers filled in a questionnaire which included the same questions as in the peer ratings. They had to rate every child in their class on the two questions mentioned above. The teachers were the class tutors. The number of hours a teacher was in the classroom varied from 3 to $7 \mathrm{~h}$ a day on average. These teachers knew their students well and were also present during lunch breaks and on the playground.

Self-ratings on bullying and victimization. All participants also rated themselves on the two bullying related questions, thus indicating how often they thought they bullied or were bullied.

Perceptions of bullying. To measure the ability to recognize bullying, video fragments which represented social situations were shown to and evaluated by participants. These video fragments were selected from a Dutch television show and two Dutch movies, which were all suitable for adolescents. The selected 14 video fragments contained bullying situations and positive social interaction situations. To check whether this categorization was unambiguous, the fragments were first evaluated by four independent researchers. The agreement between the researchers on which fragments contained bullying and which did not was $95 \%$. To examine whether non-disabled adolescents would perceive the bullying, a pilot study was conducted on 26 adolescents in a general education setting, who were matched with the group of adolescents with ASD on age and educational level. The video fragments were shown to them in their classroom. They had to score individually whether or not each fragment contained any bullying (yes/no format). The results of this pilot were in concordance with the categorization made by the researchers. The average agreement between the adolescents was $93 \%$. In total, all 14 fragments were selected, of which eight contained bullying and six contained positive social situations (i.e., no bullying). The average length of the fragments was $33 \mathrm{~s}$, ranging between 12 and $51 \mathrm{~s}$. The fragments contained the three different types of bullying that have been distinguished in previous studies (Björkqvist et al. 1992): physical bullying, verbal bullying, and relational bullying. An example of a fragment that contained bullying is a clip in which a group of boys and girls are laughing at one of their classmates and making funny faces towards her. An example of a positive situation is a clip in which a group of boys and girls are planning a surprise party for one of their friends. The 14 fragments were presented to the adolescents in four random orders, to avoid order effects. To be able to examine whether the 
adolescents with ASD would perceive and report bullying in the video fragments differently from adolescents from the general population, we also showed the video fragments to the control group of 24 adolescents without ASD, and compared the results of this group with the results from the adolescents with ASD.

We decided to examine the type of mistakes that were made by participants, in stead of a total perception score. Two types of mistakes could be made. First, the participants could misinterpret non-bullying situations, rating them as if bullying occurred in the video fragments (i.e., false positives), or secondly, they could misinterpret bullying situations, rating them as if no bullying occurred in the video fragments (i.e., false negatives). These two variables were computed by summing the mistakes that were made by each participant, and by categorizing them into false positives and false negatives. The scores on false positives could vary between 0 and 6 , the score on false negatives could vary between 0 and 8 .

Theory of Mind-Task. For assessing ToM-skills, several tests were used. First, first-order false belief was assessed by administering the Sally and Ann task (Baron-Cohen et al. 1985), and second-order false belief by administering the Ice-Cream Story (Bauminger and Kasari 1999; Perner and Wimmer 1985). In addition, an advanced test of ToM was included to further discriminate between the participants (Happé 1994). Happé (1994) developed the Strange Stories test, which consists of a set of stories about everyday situations where people say things they do not literally mean. Ten story types were included, which represent different aspects of ToM (such as white lie, pretend, double bluff, and sarcasm). The participants were presented with a story, and subsequently had to answer two questions: a comprehension question ('was it true, what X said?') and a justification question ('why did X say that?'). The answers on the justification questions were rated on a 3 -point scale: incorrect ( 0 points), partly correct (1 point), and completely correct ( 2 points). The different ToM tests were combined to create one measure for ToM. We also examined the results for all the ToM tests separately, but these results did not differ from the combined ToM test. The total score of the ToM task could vary between 0 and 22 . The reliability of all ToM tasks combined was $\alpha=.803$.

\section{Results}

First, we calculated the intercorrelations for all variables. As can be seen in Table 1, the three different ratings of bullying (i.e., teacher-, peer-, and self-report) were significantly related to each other, as were the ratings for victimization.

Subsequently, the means and standard deviations were examined for the bullying and victimization measures and the ToM task. For bullying, the means varied between 1.67 for peer- and self-reports ( $\mathrm{SD}=0.82$ and 1.13 , respectively) and 2.49 for teacher-reports $(\mathrm{SD}=1.47)$. For victimization, the means were 2.12 for teacher-reports $(\mathrm{SD}=1.25), 1.50$ for peer-reports $(\mathrm{SD}=0.78)$, and 1.63 for self-reports $(\mathrm{SD}=1.15)$. The average ToM scores was $14.60(\mathrm{SD}=4.41)$. These results show that the mean level of bullying and victimization reported by teachers is higher than the mean level of bullying and victimization reported by the adolescents themselves (peer- and self-reported).

\section{Prevalence of Bullying}

To examine the prevalence of bullying and victimization in our sample, we calculated the percentages of adolescents involved in bullying and victimization. There are several criteria to allocate adolescents into the 'bully'- or 'victim' category. According to Solberg and Olweus (2003), the most valid cutoff point for classifying adolescents as victims and/or bullies is more than 'two times a month'. However, for distinguishing the most extreme bullies and victims, more than 'once a week' is the most useful cutoff

Table 1 Intercorrelations for all variables

\begin{tabular}{|c|c|c|c|c|c|c|c|c|c|}
\hline & 1 & 2 & 3 & 4 & 5 & 6 & 7 & 8 & 9 \\
\hline 1. Bullying (teacher) & - & & & & & & & & \\
\hline 2. Bullying (peer) & $0.59 * *$ & - & & & & & & & \\
\hline 3. Bullying (self) & $0.44 * *$ & $0.38 * *$ & - & & & & & & \\
\hline 4. Victimization (teacher) & $0.23 * *$ & $0.14 * *$ & 0.09 & - & & & & & \\
\hline 5. Victimization (peer) & $0.16^{*}$ & $0.15^{*}$ & 0.11 & $0.51 * *$ & - & & & & \\
\hline 6. Victimization (self) & 0.10 & 0.01 & $0.21 * *$ & $0.38 * *$ & $0.47 * *$ & - & & & \\
\hline 7. Theory of Mind & -0.14 & -0.44 & 0.09 & $-0.16^{*}$ & 0.03 & 0.05 & - & & \\
\hline 8. False positives & -0.06 & -0.04 & 0.14 & $0.15 *$ & 0.11 & $0.15^{*}$ & -0.14 & - & \\
\hline 9. False negatives & $0.17 *$ & $0.17 *$ & 0.12 & 0.04 & 0.02 & 0.04 & $-0.18 * *$ & -0.05 & - \\
\hline
\end{tabular}

$* p<.05, * * p<.01$ 
point. To calculate the prevalence of bullying and victimization, we used these two criteria for including adolescents in the 'involved' or 'non-involved' category. The more severe criterion was that adolescents had to have a score of four or higher on the bully or victim variables, which corresponds with bullying or being bullied more than once a week. The adolescents included in these categories were the extreme bullies or victims. The less severe criterion was that adolescents had to have a score of three or higher on the bully or victim variables, which corresponds with bullying or being bullied more than once a month. The adolescents in these categories were the moderate to extreme bullies or victims. To examine the prevalence of bullying and victimization, we calculated the percentages of adolescents involved in bullying and victimization, categorized into the moderate to extreme group and the extreme group. These prevalence rates can be found in Table 2.

As can be seen in Table 2, teachers report more bullying than peers and the adolescents themselves. To test whether the differences between the teacher- and the peer- and selfratings were significant, chi squares were calculated for the four sub tables. The percentages of adolescents involved in bullying and victimization significantly differed by raters, for moderate to extreme bullies, $\chi^{2}(2, N=658)=89.23$, $p<.05$; extreme bullies, $\chi^{2}(2, N=655)=43.47, p<.05$; moderate to extreme victims, $\chi^{2}(2, N=658)=55.00$, $p<.05$; and extreme victims, $\chi^{2}(2, N=655)=41.91$, $p<.05$. Subsequently, the standardized residuals were examined to determine which cells contributed most in creating these differences (Haberman 1973). The standardized residuals are calculated by subtracting the expected frequencies from the observed frequencies, and dividing this by the square root of the expected frequencies. For all four sub tables, the standardized residuals of the teacher report indicated that they reported significantly more bullying and victimization than expected ( $r=6.4,4.4,5.3$, and 4.3 , respectively). Furthermore, the standardized residuals of the peer report indicated that they reported significantly less bullying and victimization than expected ( $r=-4.8,-4.0,-4.4$, and -4.4 , respectively). An interesting finding concerning the prevalence of bullying and victimization reported by teachers is that they significantly reported far more bullying and victimization than the adolescents reported about their peers and about themselves. Furthermore, peers reported significantly less bullying and victimization than expected. These results may seem to be in contradiction with the descriptive results presented earlier, because the means for the peer- and selfreports on bullying were equal. However, although the means are equal, the distribution of the scores is different, which explains the different prevalence rates.

\section{Perceptions of Bullying}

First, we examined the self-reported perception of bullying in our sample. The mean score on all video fragments was 12.77 ( $\mathrm{SD}=1.14$, range $0-14$ ) and the average number of false positive and false negative mistakes was .69 $(\mathrm{SD}=1.04)$ and $.65(\mathrm{SD}=.83)$, respectively. Furthermore, to examine whether the ASD adolescents' scores on the video fragments were significantly different from a distribution based on chance, we conducted binomial tests on the 14 video fragments. The results from these tests were significant for all 14 items $(p<.001)$, indicating that the ASD adolescents scored significantly better than could be expected by chance. We also compared the results of the ASD adolescents with results of the control group of adolescents without ASD. Results from a one-way ANOVA showed that the ASD group did not significantly differ from the control group in the scores on the video fragments $(F[1]=.589, p=.443)$. All of these findings indicate that the ASD adolescents made very few false positive and false negative mistakes, and were as able as adolescents without ASD to perceive and report on bullying.
Table 2 Percentages of adolescents with ASD who are Involved and non-involved in bullying and victimization

\begin{tabular}{|c|c|c|c|c|}
\hline & \multicolumn{2}{|c|}{$\begin{array}{l}\text { More than once a month } \\
\text { (moderate to extreme group) }\end{array}$} & \multicolumn{2}{|c|}{$\begin{array}{l}\text { More than once a week } \\
\text { (extreme group) }\end{array}$} \\
\hline & Involved (\%) & Non-involved (\%) & Involved (\%) & Non-involved (\%) \\
\hline \multicolumn{5}{|l|}{ Bullies } \\
\hline Teacher-report & 46 & 54 & 27 & 73 \\
\hline Peer-report & 15 & 85 & 4 & 96 \\
\hline Self-report & 19 & 81 & 12 & 88 \\
\hline \multicolumn{5}{|l|}{ Victims } \\
\hline Teacher-report & 30 & 70 & 18 & 82 \\
\hline Peer-report & 7 & 93 & 0.4 & 99.6 \\
\hline Self-report & 17 & 83 & 10 & 90 \\
\hline
\end{tabular}


Table 3 Linear regression analyses of Theory of Mind, bullying, and victimization on false positives based on teacher- and self-reported bullying and victimization

\begin{tabular}{|c|c|c|c|c|c|c|}
\hline & \multicolumn{6}{|c|}{ False positives } \\
\hline & \multicolumn{3}{|c|}{ Teacher report } & \multicolumn{3}{|c|}{ Self report } \\
\hline & $B$ & $\operatorname{SE}(B)$ & $\beta$ & $B$ & $\mathrm{SE}(B)$ & $\beta$ \\
\hline ToM & -0.02 & 0.01 & -0.11 & -0.30 & 0.01 & -0.16 \\
\hline Bullying & -0.05 & 0.04 & -0.09 & -0.01 & 0.05 & -0.01 \\
\hline Victimization & $0.10^{*}$ & 0.05 & $0.15^{*}$ & $0.12 *$ & 0.06 & $0.16^{*}$ \\
\hline
\end{tabular}

Note: ToM $=$ Theory of Mind

$* p<.05$

Our main research question concerned the self-reported perception of bullying (categorized in false positive and false negative mistakes) and its relation with ToM, the level of bullying and the level of victimization. Three multiple linear regression analyses were performed to explore the associations between ToM, bullying, victimization and the type of mistakes. The results were examined separately for teacher-, peer-, and self-reported bullying. In all three analyses, ToM and the level of bullying and victimization were the independent variables, and the number of false positive mistakes was the dependent variable. For peer reported bullying and victimization, the results were not significant. The results of the analyses with teacher- and self-reported bullying and victimization can be found in Table 3 .

As can be seen in Table 3, both teacher- and selfreported victimization were significantly related to the number of false positive mistakes, $F(3,189)=2.83$, $p=.005$, and $F(3,191)=3.08, p=.004$, respectively. This indicates that the more adolescents were bullied, as reported by teachers and themselves, the more they misinterpreted non-bullying situations as bullying. The proportion of variance explained by all variables included in the analyses was $4.3 \%$ for teacher reported victimization and $5 \%$ for peer reported victimization.

Second, we conducted three multiple linear regression analysis on ToM, bullying, victimization, and false negatives, one on teacher reported bullying and victimization, one on peer reported bullying and victimization, and one on self-reported bullying and victimization. In all three analyses, ToM and the level of bullying and victimization were the independent variables, and the number of false negative mistakes made was the dependent variable. The results from the analysis with self-reported bullying and victimization were not significant. The results from teacher- and peer-reported bullying and victimization can be found in Table 4.

As can be seen in Table 4, ToM and teacher reported bullying were significant predictors in the first analysis,
Table 4 Linear regression analyses of Theory of Mind, bullying, and victimization on false negatives based on teacher- and peer-reported bullying and victimization

\begin{tabular}{|c|c|c|c|c|c|c|}
\hline & \multicolumn{6}{|c|}{ False negatives } \\
\hline & \multicolumn{3}{|c|}{ Teacher report } & \multicolumn{3}{|c|}{ Peer report } \\
\hline & $B$ & $\mathrm{SE}(B)$ & $\beta$ & $B$ & $\mathrm{SE}(B)$ & $\beta$ \\
\hline ToM & $-0.04 *$ & 0.02 & $-0.18^{*}$ & $-0.04 *$ & 0.02 & $-0.18 *$ \\
\hline Bullying & $0.13^{*}$ & 0.05 & $0.18^{*}$ & $0.22 *$ & 0.09 & $0.18 *$ \\
\hline Victimization & -0.00 & 0.06 & -0.01 & 0.02 & 0.09 & 0.02 \\
\hline
\end{tabular}

Note: $T o M=$ Theory of Mind

$* p<.05$

$F(3,189)=4.48, p=.005$. This means that the higher the level of ToM, the less false negative mistakes the adolescents made and the higher the level of bullying, as reported by teachers, the more they misinterpreted bullying situations as non-bullying. The proportion of variance explained by all variables in the analysis was $7 \%$. In the analysis with peer reported bullying and victimization, ToM and peer reported bullying were significant predictors of the number of false negative mistakes made, $F(3,191)=4.56$, $p=.004$. This indicates that the higher the level of peerreported bullying, the more adolescents misinterpreted bullying situations as non-bullying. This model explained $7 \%$ of the variance in false negative mistakes, when all variables are taken account of.

\section{Discussion}

The aims of the present study were: (a) to examine the prevalence of bullying and victimization among adolescents with ASD, and (b) to examine whether adolescents with ASD are able to perceive bullying and victimization and which factors are related to this perception.

\section{Prevalence of Bullying and Victimization}

It may be concluded that bullying is prevalent among adolescents with ASD in special education schools. An important finding is that a large discrepancy exists between the level of bullying reported by teachers on the one hand, and by peers and adolescents themselves on the other hand, with teachers reporting higher levels of bullying than peers and adolescents. The prevalence rates based on peer- and self-reports are in line with prevalence rates in children in general education settings found in other studies (Eslea et al. 2004), in which prevalence rates of 2 to $17 \%$ were found, based on self-reports. The prevalence of bullying in our sample according to teachers is much higher than in children in general education settings. This is in contrast to 
results on studies on bullying and victimization in children in general education settings, showing that teachers generally tend to report lower levels of bullying than the adolescents themselves (Beaty and Alexeyev 2008; Salmivalli 2002). In typically developing children, the main explanation for this lower level of bullying reported by teachers is that bullying often occurs outside the classroom (in toilets, lunchrooms, playgrounds, etc.), situations in which teachers are not always present. In our sample, adolescents with ASD attend special education schools, in which each class has their own teacher during most of the day. During breaks, the students are under continuous supervision of several teachers, in lunchrooms as well as on the playground. Therefore, the teachers in our sample are probably able to report most of the bullying behavior that occurs, and this may explain the higher percentages of both bullying and victimization in the current study compared to outcomes of other studies in this area. The level of bullying and victimization reported by peers in the present study was significantly lower than the amount of bullying and victimization reported by teachers and by the adolescents themselves. This is in line with results from previous studies in children in general education settings, in which the level of bullying and victimization reported by peers is generally lower than the level of bullying and victimization reported by adolescents themselves (Salmivalli 2002; Stassen Berger 2007).

The prevalence rates of bullying of adolescents with ASD in our sample, as reported by peers, is in agreement with the prevalence rates found in adolescents with ASD in general education settings. In a study by Montes and Halterman (2007), 26\% of the adolescents with ASD were classified as bullies.

The prevalence rates for victimization (moderate to severe victims) varied from 7 to $30 \%$, with peers reporting the least victimization and teachers reporting the most victimization. These rates indicate that victimization is also a prevalent problem in adolescents with ASD attending special education. As in bullying, the most striking result was that teachers reported far more victimization than the adolescents themselves. This difference may be explained by the same reasons given above concerning bullying.

The prevalence rates in the present study are in line with prevalence rates of victimization in children in general education settings in 28 countries (Due et al. 2005). However, the rates found in the present study are much lower than those found by Little (2001), who found a prevalence rate of victimization of $75 \%$ in children and adolescents with Asperger syndrome attending general education settings. The level of victimization in adolescents with ASD in special education is thus much lower than the level of victimization in adolescents with Asperger syndrome in general education settings. Although the victimization does not completely disappear, making the transition from general to special education settings does seem to decrease the prevalence rates of victimization. An explanation for this difference in victimization may be that all adolescents attending these special education schools have ASD. Therefore, the specific characteristics which makes special needs children and adolescents obvious targets in general education settings, such as their low social competence and the low number of friendships (Martlew and Hodson 1991; Whitney et al. 1992) are not exceptional anymore, which may reduce the victimization rates. Furthermore, the structure and routine organization in special education schools seems to be higher than in general education settings, which might reduce the disruptive behavior of adolescents with ASD.

It is important to note that no conclusions can be drawn about who the best reporter of bullying and victimization is. Teacher reports may be valuable because they contain information gained by adults who are relative outsiders of the adolescent peer group. However, what teachers report differs from what the adolescents perceive about their own situation and about their peer group. They may all have different interpretations of the bullying that occurs in their class. Hence the different reports may represent different aspects of bullying.

\section{Perceptions of Bullying}

Our findings provide several indications that the perceptions of adolescents with ASD on bullying were likely to be accurate. The ASD adolescents made very few mistakes on the video fragments and performed much better than could have been expected by change, as indicated by the results from the binominal tests. In addition, their perceptions on bullying did not differ significantly from the perceptions of adolescents from the general population. These are important findings, because adolescents with ASD are found to have deficits in their social perception. However, because the current study is among the first to examine peer-, and self-reported bullying among adolescents with ASD, further research is warranted to replicate our findings.

Another important finding of the present study was that the more often adolescents were bullied, as rated by teachers and the adolescents themselves, the more they misinterpreted non-bullying situations as bullying (i.e., had higher levels of false positive mistakes), even though the effect sizes of these findings were relatively small. Adolescents who are bullied a lot may experience many negative interactions and situations, and as a consequence may be biased in their perception and interpret neutral or positive situations more negatively. That only teacher- and selfreported victimization were related to the number of false 
positives is not surprising. The adolescents who rate themselves as being victims (whether it is true or not) will have experienced negative situations and thus may have a bias in their perception.

Furthermore, the teacher probably rated the adolescents who were actually bullied, or at least had experienced negative situations, as victim, because they were in the position to observe most bullying and victimization. Peers, on the other hand, probably do not perceive all victimization that occurs, because of their limited insight in social processes. Victimization of their class members could especially be hard to observe for them, because it does not directly involve themselves. The level of bullying was not significant in predicting the number of false positives. And, surprisingly, ToM was not related to the number of false positives.

Another striking result in the current study concerns the false negative mistakes. We found that the more often adolescents bullied, as rated by teachers and peers, the more they misinterpreted bullying situations as non-bullying. As was the case with the false positive mistakes, the effect sizes for these findings were also relatively small. The relationship between the level of bullying and false negative mistakes could be explained in two ways. First, it is possible that adolescents who bully a lot make mistakes in processing social information, as was found in aggressive adolescents (Crick and Dodge 1996). Second, this deficit in perception could be a form of cognitive dissonance. These adolescents may know that their own bullying behavior is not permitted, and as a consequence they rate bullying situations as non-bullying, because by denying certain behavior as bullying they may try to condone their own bullying behavior. This may also explain why only teacher- and peer-rated bullying were significant predictors for the number of false negative mistakes made, the adolescents who report their own bullying behavior are less likely to make more false negative mistakes than adolescents who deny their own bullying. Furthermore, ToM was negatively related to the number of false negatives, implying that the better a participants' ToM abilities are, the fewer false negative mistakes he/she made. This relationship could be expected based on common sense; the better understanding adolescents' have of mental states of others, the better they can perceive and interpret social situations.

\section{Strengths, Limitations and Implications}

The present study extends the literature in several ways. First, bullying and victimization have never been studied in adolescents with ASD attending special education. Second, three different sources of information for measuring bullying and victimization were used. Third, we examined the perception of bullying through video fragments, which, to our knowledge, has never been done in previous research on bullying.

The present study also has some shortcomings. First, we found that the level of bullying and victimization were significant predictors of the number of false negative and false positive mistakes, respectively. However, because the current study was correlational, no conclusions could be drawn about causal influences. It could be that adolescents with high levels of bullying and victimization develop a distorted perception as a result of these high levels of bullying and victimization. On the other hand, it may also be possible that a distorted perception in adolescents results in a high involvement in bullying and victimization.

Second, in bullying research in general education settings, the results are often examined for boys and girls separately. Boys usually bully more than girls (Haynie et al. 2001) and use more direct, physical types of bullying, while girls are more involved in indirect, relational bullying (Rivers and Smith 1994). In the present study, we could not examine the results for boys and girls, because the sample size of girls was too small. This was not surprising, because ASD is more prevalent in boys than in girls. However, in future research this could be an important topic, because results from past research have shown that the amount and type of bullying differs for boys and girls.

Third, differences in prevalence of bullying and victimization and in the perception of bullying may exist between the different subtypes of ASD. However, in the present study we could not distinguish between these types of ASD because the sample sizes of these groups were too small.

Next to these strengths and limitations, an implication for practice can be derived from the current study. We found that the more adolescents bullied themselves or were bullied by others, the more mistakes they made in their perception of bullying. This is important in designing interventions, because these results imply that interventions should focus on improving the perception of bullying and victimization. Up to now, most interventions focus on psycho education, behavior modification, teacher training, or the development of anti-bullying policies (Smith et al. 2003; Vreeman and Carroll 2007). To our knowledge, no interventions have been evaluated in adolescents with ASD, and no attention has been given to the perception of bullying, while this may especially be important in adolescents with ASD. The results from the present study imply that interventions aimed at reducing bullying among adolescents with ASD might specifically focus on altering the perception of bullying and victimization. 
Open Access This article is distributed under the terms of the Creative Commons Attribution Noncommercial License which permits any noncommercial use, distribution, and reproduction in any medium, provided the original author(s) and source are credited.

\section{References}

Baron-Cohen, S. (2000). Theory of mind and autism: A fifteen year review. In S. Baron-Cohen, H. Tager-Flusberg, \& D. J. Cohen (Eds.), Understanding other minds: Perspectives from developmental cognitive neuroscience (pp. 3-20). New York: Oxford University Press.

Baron-Cohen, S., Leslie, A. M., \& Frith, U. (1985). Does the autistic child have a 'theory of mind'? Cognition, 21, 37-46.

Baron-Cohen, S., Jolliffe, T., Mortimore, C., \& Robertson, M. (1997). Another advanced test of theory of mind: Evidence from very high functioning adults with autism or Asperger Syndrome. Journal of Child Psychology and Psychiatry, 38, 813-822.

Bauminger, N., \& Kasari, C. (1999). Brief report: Theory of mind in high-functioning children with autism. Journal of Autism and Developmental Disorders, 29, 81-86.

Bauminger, N., \& Kasari, C. (2000). Loneliness and friendship in high-functioning children with autism. Child Development, 71, $447-456$.

Baumeister, A. L., Storch, E. A., \& Geffken, G. R. (2008). Peer victimization in children with learning disabilities. Child and Adolescent Social Work Journal, 25, 11-23.

Beaty, L. A., \& Alexeyev, E. B. (2008). The problem of school bullies: What the research tells us. Adolescence, 43, 1-11.

Björkqvist, K., Lagerspetz, K., \& Kaukiainen, A. (1992). Do girls manipulate and boys fight? Developmental trends in regard to direct and indirect aggression. Aggressive Behaviour, 18, 117-127.

Chamberlain, B., Kasari, C., \& Rotheram-Fuller, E. (2007). Involvement or isolation? The social networks of children with autism in regular classrooms. Journal of Autism and Developmental Disorders, 37, 230-242.

Conti-Ramsden, G., \& Botting, N. (2004). Social difficulties and victimization in children with SLI at 11 years of age. Journal of Speech, Language, and Hearing Research, 47, 145-161.

Crick, N. R., \& Dodge, K. A. (1996). Social information-processing mechanisms in reactive and proactive aggression. Child Development, 67, 993-1002.

Due, P., Holstein, B. E., Lynch, J., Diderichsen, F., Nic Gabhein, S., Scheidt, P., et al. (2005). Bullying and symptoms among schoolaged children: International comparative cross sectional study in 28 countries. European Journal of Public Health, 15, 128-132.

Eslea, M., Menesini, E., Morita, Y., O’Moore, M., Mora-Merchán, J. A., Pereira, B., et al. (2004). Friendship and loneliness among bullies and victims: Data from seven countries. Aggressive Behavior, 30, 71-83.

Fine, S. E., Trentacosta, C. J., Izard, C. E., Mostow, A. J., \& Campbell, J. L. (2004). Anger perception, caregivers' use of physical discipline, and aggression in children at risk. Social Development, 13, 213-228.

Frith, U., \& Hill, E. (2004). Autism: Mind and brain. New York: Oxford University Press.

Haberman, S. J. (1973). The analysis of residuals in cross-classified tables. Biometrics, 29, 205-220.

Happé, F. G. E. (1994). An advanced test of theory of mind: Understanding of story characters' thoughts and feelings by able autistic, mentally handicapped, and normal children and adults. Journal of Autism and Developmental Disorders, 24, 129-154.

Haq, I., \& Le Couteur, A. (2004). Autism spectrum disorder. Medicine, 32, 61-63.
Haynie, D. L., Nansel, T., Eitel, P., Davis Crump, A., Saylor, K., Yu, K., et al. (2001). Bullies, victims, and bully/victims: Distinct groups of at-risk youth. Journal of Early Adolescence, 21, 29-49.

Hodges, E. V. E., Boivin, M., Vitaro, F., \& Bukowski, W. M. (1999). The power of friendship: Protection against an escalating cycle of peer victimization. Developmental Psychology, 35, 94-101.

Kumpulainen, K., Räsänen, E., Henttonen, I., Almqvist, F., Kresanov, K., Linna, S., et al. (1998). Bullying and psychiatric symptoms among elementary school-age children. Child Abuse and Neglect, 22, 705-717.

Kumpulainen, K., Räsänen, E., \& Puura, K. (2001). Psychiatric disorders and the use of mental health services among children involved in bullying. Aggressive Behaviour, 27, 102-110.

Little, L. (2001). Peer victimization of children with Asperger Spectrum Disorders. Journal of the American Academy of Child and Adolescent Psychiatry, 40, 995-996.

Little, L. (2002). Middle-class mother's perceptions of peer and sibling victimization among children with Asperger's syndrome and nonverbal learning disorders. Issues in Comprehensive Pediatric Nursing, 25, 43-57.

Loveland, K. A., Pearson, D. A., Tunali-Kotoski, B., Ortegon, J., \& Cullen Gibbs, M. (2001). Judgment of social appropriateness by children and adolescents with autism. Journal of Autism and Developmental Disorders, 31, 367-376.

Martlew, M., \& Hodson, J. (1991). Children with mild learning difficulties in an integrated and in a special school: Comparisons of behaviour, teasing, and teachers' attitudes. British Journal of Educational Psychology, 61, 355-372.

Matson, J. L., \& Nebel-Schwalm, M. (2007). Assessing challenging behaviors in children with autism spectrum disorders: A review. Research in Developmental Disabilities, 28, 567-579.

McClintock, K., Hall, S., \& Oliver, C. (2003). Risk markers associated with challenging behaviors in people with intellectual disabilities: A meta-analytic study. Journal of Intellectual Disability Research, 47, 405-416.

Montes, G., \& Halterman, J. S. (2007). Bullying among children with autism and the influence of comorbidity with ADHD: A population-based study. Ambulatory Pediatrics, 7, 253-257.

Nordhagen, R., Nielsen, A., Stigum, H., \& Köhler, L. (2005). Parental reported bullying among Nordic children: A populationbased study. Child: Care, Health and Development, 31, 693701.

Olweus, D. (1991). Bully/victim problems among schoolchildren: Basic facts and effects of a school-based intervention program. In D. Pepler \& K. Rubin (Eds.), The development and treatment of childhood aggression. Hillsdale, NJ: Erlbaum.

Olweus, D. (1993). Bullying at school: What we know and what we can do. Cambridge, MA: Blackwell.

Perner, J., \& Wimmer, H. (1985). 'John thinks that Mary thinks that'. Attribution of second-order beliefs by 5- to 10-year-old children. Journal of Experimental Child Psychology, 390(43), 7-471.

Pierce, K., Glad, K. S., \& Schreibman, L. (1997). Social perception in children with autism: An attentional deficit? Journal of Autism and Developmental Disorders, 27, 265-282.

Repacholi, B., \& Slaughter, V. (2003). Individual differences in theory of mind: Implications for typical and atypical development. New York: Psychology Press.

Rivers, I., \& Smith, P. K. (1994). Types of bullying behavior and their correlates. Aggressive Behavior, 20, 359-368.

Salmivalli, C. (2002). Is there an age decline in victimization by peers at school? Educational Research, 44, 269-277.

Scholte, R. H. J., de Kemp, R. A. T., Haselager, G. J. M., \& Engels, R. C. M. E. (2007). Longitudinal stability in bullying and victimisation in childhood and adolescence. Journal of Abnormal Child Psychology, 35, 217-238. 
Schultz, D., Izard, C. E., \& Ackerman, B. P. (2000). Children's anger attribution bias: Relations to family environment and social adjustment. Social Development, 9, 284-301.

Smith, P. K., \& Sharp, S. (1994). School Bullying: Insights and Perspectives. London: Routledge.

Smith, P. K., Morita, Y., Junger-Tas, J., Olweus, D., Catalano, R., \& Slee, P. (1999). The nature of school bullying: A cross-national perspective. London \& New York: Routledge.

Smith, P. K., Ananiadou, K., \& Cowie, H. (2003). Interventions to reduce school bullying. The Canadian Journal of Psychiatry, 48, 591-599.

Solberg, M. E., \& Olweus, D. (2003). Prevalence estimation of school bullying with the Olweus bully/victim questionnaire. Aggressive Behavior, 29, 239-268.
Stassen Berger, K. (2007). Update on bullying at school: Science forgotten? Developmental Review, 27, 90-126.

Van Cleave, J., \& Davis, M. M. (2006). Bullying and peer victimization among children with special health care needs. Pediatrics, 118, 1212-1219.

Vreeman, R. C., \& Carroll, A. E. (2007). A systematic review of school-based interventions to prevent bullying. Archives of Pediatrics and Adolescent Medicine, 161, 78-88.

Whitney, I., \& Smith, P. K. (1993). A survey of the nature and extent of bullying in junior/middle and secondary schools. Educational Research, 35, 3-25.

Whitney, I., Nabuzoka, D., \& Smith, P. K. (1992). Bullying in schools: Mainstream and special needs. Support for Learning, 7, 3-7. 